\title{
An application of ANP for ranking different factors influencing on demand for auto parts
}

\author{
Ali Zarepour ${ }^{a^{*}}$ and Hossein Ali Momeni ${ }^{\mathrm{b}}$
}

${ }^{a}$ Department of Management, Ghazvin Branch, Islamic Azad University, Ghazvin, Iran

${ }^{b}$ Department of Management, Karaj Branch, Islamic Azad University, Alborz, Iran

\section{CHR ON I C L E ABSTRACT}

Article history:

Received July 28, 2013

Accepted 14 January 2014

Available online

March 32014

Keywords:

Analytical hierarchy process

ANP

Auto parts

Group decision making

\begin{abstract}
This paper presents an empirical investigation to study different factors influencing auto parts in different regions of Iran. The study has asked some experts who worked for the biggest auto parts supplier named SaipaYadak to express their insights about important factors influencing demand for auto parts in different region and their insights have grouped into four categories of parts related issues, weather conditions, regional as well as cultural factors. The study has been applied in five different regions of country including central, south, north, west and east. The study has used analytical network process (ANP) to rank different factors and the results indicate that regional factors is the most important item followed by cultural issues, auto parts and weather conditions.
\end{abstract}

\section{Introduction}

There are different advantages on having car in people's life and leisure. One advantage of owning a car is to have our own transportation to when and where we wish. Another advantage to owning a car is the feeling of accomplishment that comes with owning a good item. There are over 60 million cars produced on the market and one primary need is to have the access to necessary auto parts. An auto part supplier has to know more about demand and different factors influencing it (Scherer, 1982). In fact, demand for auto parts may depend on various factors including weather condition, road conditions, etc. (Klier \& Rubenstein, 2006). Lai et al. (2008) presented a technique for packaging system assessment, which considers the division manager's span of control, addressed the design of packaging and the corresponding logistics processes, and incorporated both cost and environmental effects. They also used a framework to illustrate the implementation of a case study of a major US automaker. According to Santucci (1997), auto industry has shifted from a regional industry to a global industry and the original equipment supplier base has been pulled in the same direction. The globalization process has paralleled the consolidation of the supplier base that has occurred. There are

*Corresponding author. Tel: +989123232940

E-mail addresses: zarepour54@gmail.com (A. Zarepour) 
several reasons for sharing the risk associated with automakers since the sector has to handle various issues (Tabeta \& Rahman, 1999). Türkcan (2011) examined the development of vertical intraindustry trade (IIT) in the auto-parts industry as an indicator for international fragmentation of the production process between Austria and its 29 trading partners, and different country-specific factors recommended by the fragmentation literature were examined based on some panel econometrics as well as some historical data over the period 1996-2006. They reported that a substantial portion of IIT in the Austrian auto-parts industry was vertical IIT.

\section{The proposed study}

One of the issues of production planning in auto parts industry is to find important factors influencing demand including weather conditions, regional factors, etc. Saipa Yadak Company was established in 1992 to supply spare parts and after-sales services for an automaker firm named Saipa. Saipa Yadak has applied a supporting method of development by performing warranty policies while being active in international commercial world of spare parts at the same time, which allows SAIPA updating its after-sale industry and developing its network in the world. The proposed study of this paper first has asked 45 experts to determine important factors influencing demand for auto parts and 19 factors have been determined summarized in Table 1 as follows,

Table 1

Different factors influencing demand for auto parts

\begin{tabular}{lll}
\hline Road accidents & City road conditions & Car guarantee terms \\
City accidents & Auto parts life cycle & Culture of how to use cars \\
Humidity & Auto parts usage & Culture of how to repair cars \\
Weather dryness & Quality of auto parts & Distance from other cities \\
Temperature & Methods of sales, pulls versus push & Embargo and political affairs \\
Price & Quality of car produced & \\
Road conditions & Auto parts guarantee conditions & \\
\hline
\end{tabular}

As we can observe from the results of Table 1, there are 19 items influencing demand for auto parts in Iran. After performing an in-depth discussion, we have reduced the items into 12 factors summarized in Table 2 as follows.

\section{Table 2}

The summary of 12 factors influencing demand for auto parts

Road accidents

Weather conditions

City road conditions

Auto parts guarantee conditions
Highway conditions

Auto parts life cycle

Auto parts usage

Car guarantee terms
Quality of auto parts

Methods of sales, pulls versus push

Culture of how to repair cars

Culture of how to use cars

Next, we have used factor analysis to group these factors and the results are summarized in Table 3 as follows,

\section{Table 3}

The results of factor analysis

\begin{tabular}{llll}
\hline Factor & 1 & 2 & 3 \\
\hline Car guarantee terms & .963 & \\
\hline Auto parts usage & .927 & & \\
Quality of auto parts & .870 & .853 \\
Culture of deriving & & .809 \\
City road conditions & .777 & .477 \\
Auto parts guarantee & .764 & .966 \\
Life cycle & & .896 \\
Number of accidents & & .907 & \\
Weather conditions & & & .835 \\
Highway road conditions & & & -.807 \\
\hline Sales methods & & & \\
Culture of repairing car & & & \\
\hline
\end{tabular}


According to the results of Table 3, the first group consists of 5 items including car guarantee terms, auto parts usage, quality of auto parts, auto parts guarantee and life cycle and we name it auto parts group. The second item consists of one item named weather conditions. The third group includes three factors including city road conditions, number of accidents and highway road conditions and we name this group as regional factors. Finally, the last group consists of culture of deriving, auto parts guarantee and sales methods and named as cultural factors. The study has applied Pearson correlation test as well as t-student to examine the effects of these factors and Table 4 shows details of our findings.

\section{Table 4}

The summary of Pearson correlation and t-student test on the effects of different factors on demand for auto parts

\begin{tabular}{lccc}
\hline Factor & Pearson correlation & t-student & Result \\
\hline Auto parts related issues & 0.8936 & 3.4482 & Confirmed \\
Weather condition & 0.8536 & 2.8388 & Confirmed \\
Regional factors & 0.9396 & 4.7568 & Confirmed \\
Cultural factors & 0.8542 & 2.8456 & Confirmed \\
\hline Total & 0.9278 & 4.3079 & Confirmed \\
\hline
\end{tabular}

According to the results of Table 4, all four factors individually and combined influence on demand for auto parts.

\section{Analytical network process}

Next, we have used analytical network process (ANP) (Saaty, 2001, 2004) to rank different factors based on their relative importance. Table 5 demonstrates the results of our survey for ranking various factors in terms of five regions.

Table 5

The summary of ranking of different factors associated with auto parts based on ANP method

\begin{tabular}{cccccccccccc}
\hline \multirow{2}{*}{ Sub-component } & \multicolumn{2}{c}{ North } & \multicolumn{2}{c}{ South } & \multicolumn{2}{c}{ East } & \multicolumn{2}{c}{ West } \\
& Weight & Rank & Weight & Rank & Weight & Rank & Weight & Rank & Weight & Rank \\
\hline Guarantee & 0.098 & 5 & 0.073 & 5 & 0.098 & 5 & 0.253 & 2 \\
Parts usage & 0.2 & 3 & 0.249 & 2 & 0.217 & 2 & 0.178 & 3 \\
Quality & 0.319 & 1 & 0.282 & 1 & 0.386 & 1 & 0.095 & 5 \\
Parts guarantee & 0.102 & 4 & 0.166 & 4 & 0.146 & 4 & 0.183 & 4 & 0.114 \\
Life cycle & 0.281 & 2 & 0.23 & 3 & 0.153 & 3 & 0.291 & 1 \\
\hline
\end{tabular}

The results of Table 5 indicate that auto parts' quality and life cycle play essential role for demand in all regions of the country. Similarly, Table 6 shows the results of the implementation of ANP method for ranking various factors associated with regional factors.

Table 6

The summary of ranking of regional factors based on ANP method

\begin{tabular}{cccccccccc}
\hline \multirow{2}{*}{ Sub-component } & \multicolumn{2}{c}{ North } & \multicolumn{2}{c}{ South } & \multicolumn{2}{c}{ East } & \multicolumn{2}{c}{ West } & \multicolumn{2}{c}{ Center } & Weight & Rank & Weight & Rank \\
& Weight & Rank & Weight & Rank & Weight & & 0.402 & 1 & 0.351 \\
\hline Road conditions & 0.317 & 2 & 0.364 & 1 & 0.308 & 3 & 2 & 0.385 & 2 \\
Highway conditions & 0.394 & 1 & 0.299 & 3 & 0.357 & 1 & 0.212 & 3 \\
Accidents & 0.289 & 3 & 0.337 & 2 & 0.335 & 2 & 0.213 & 3 \\
\hline
\end{tabular}

According to the results of Table 6, highway conditions and the numbers of accidents are important factors influencing demand for auto parts. Finally, Table 7 shows details of ranking the cultural affairs. According to the results of Table 7, driving culture is number priority for demand on auto parts followed by sales methods and maintenance issues. 
Table 7

The summary of ranking of cultural factors based on ANP method

\begin{tabular}{cccccccccccc}
\hline \multirow{2}{*}{ Sub-component } & \multicolumn{2}{c}{ North } & \multicolumn{2}{c}{ South } & \multicolumn{2}{c}{ East } & \multicolumn{2}{c}{ West } & \multicolumn{2}{c}{ Center } \\
\cline { 2 - 12 } & Weight & Rank & Weight & Rank & Weight & Rank & Weight & Rank & Weight & Rank \\
\hline Driving culture & 0.471 & 1 & 0.46 & 1 & 0.369 & 1 & 0.488 & 1 & 0.448 & 1 \\
Maintenance & 0.099 & 3 & 0.215 & 3 & 0.34 & 2 & 0.239 & 3 & 0.265 & 3 \\
Sales methods & 0.43 & 2 & 0.325 & 2 & 0.291 & 3 & 0.273 & 2 & 0.287 & 2 \\
\hline
\end{tabular}

\section{Conclusion}

In this paper, we have presented an empirical investigation to study the impact of different factors on demand for auto parts in Iran. The study has applied analytical network process to rank different factors and categorized them in terms of four groups of auto parts related, regional issues, weather conditions and cultural factors. In terms of auto parts and their components, quality and life cycle play the most important role while in terms of regional affairs, highway conditions and the numbers of accidents are important factors influencing demand for auto parts. Finally, cultural affairs are the last component of the survey where driving culture is number priority for demand on auto parts followed by sales methods and maintenance issues.

\section{Acknowledgement}

The authors would like to thank the anonymous referees for their comments on earlier version of this paper.

\section{References}

Klier, T. H., \& Rubenstein, J. M. (2006). Competition and trade in the US auto parts sector. Chicago Fed Letter, 222, 1-4.

Lai, J., Harjati, A., McGinnis, L., Zhou, C., \& Guldberg, T. (2008). An economic and environmental framework for analyzing globally sourced auto parts packaging system. Journal of Cleaner Production, 16(15), 1632-1646.

Santucci, M. (1997). Executive Insights: Globalization of the Auto Parts Industry. Journal of International Marketing, 5(3).

Saaty, T. L. (2001). Analytic network process. In Encyclopedia of Operations Research and Management Science (pp. 28-35). Springer US.

Saaty, T. L. (2004). Fundamentals of the analytic network process - multiple networks with benefits, costs, opportunities and risks. journal of systems science and systems engineering, 13(3), 348-379.

Scherer, F. M. (1982). Demand-pull and technological invention: Schmookler revisted. The Journal of Industrial Economics, 30(3), 225-237.

Tabeta, N., \& Rahman, S. (1999). Risk sharing mechanism in Japan's auto industry: The keiretsu versus independent parts suppliers. Asia Pacific Journal of Management, 16(3), 311-330.

Türkcan, K. (2011). Vertical intra-industry trade and product fragmentation in the auto-parts industry. Journal of Industry, Competition and Trade, 11(2), 149-186. 